\title{
Efficient Solution-Processed Blue and Yellow Phosphorescent Organic Light- emitting Diodes Using Binary Blend Hosts
}

\author{
Yuxin GUAN ${ }^{1}$, Wenjing LIN $^{2}$, Qiannan WANG ${ }^{3}$, Pengchao ZHOU ${ }^{4}$, Bin WEI ${ }^{4}$, \\ Yingjie LIAO ${ }^{4 *}$
}

${ }^{1}$ School of Materials Science and Engineering, Shanghai University, 99 Shangda Road BaoShan District, Shanghai, 20444, P.R.China

${ }^{2}$ OLED (Shanghai) Material Tech Co., Ltd \& Shanghai Shinsee Optoelectronics Technology Co., 666 Ltd, Xianing Road, Shanghai, 201506, P.R.China

${ }^{3}$ Sino European School of Technology of Shanghai, Shanghai University, 99 Shangda Road BaoShan District, Shanghai, 20444, P.R.China

${ }^{4}$ School of Mechatronic Engineering and Automation, Shanghai University, 99 Shangda Road BaoShan District, Shanghai, 20444, P.R.China

crossref http://dx.doi.org/10.5755/j02.ms.24679

Received 25 November 2019; accepted 17 June 2020

\begin{abstract}
The appropriate hosts of emitting layers (EMLs) play an important role in determining the overall performance of solution-processed phosphorescent organic light emitting diodes (PhOLEDs). We have investigated the effect of three species of host molecules, 1,3-bis(carbazol-9-yl)benzene (mCP), 10-(4-(5,5dimethylbenzofuro[3,2-c]acridin-13(5H)yl)phenyl)-10-phenylanthracen-9(10H)-one (DpAn-5BzAc) and poly(9-vinylcarbazole) (PVK), on the performance of solution-processed blue and yellow PhOLEDs. We have found that compared to the widely used single-host EMLs, the devices using the binary blend of mCP: DpAn5BzAc as hosts, can achieve more efficient optoelectrical characteristics. The maximum current efficiencies of 11.84 and 16.61 have been realized for blue and yellow OLEDs, respectively. The superior electroluminescence performance for binary blend host-based PhOLEDs was attributed to the enhanced charge carrier balance and multi-component miscibility, which has a dramatic influence on the morphology of the emissive layer. These results demonstrate the great potential of the multi-hosts in solution-processed organic optoelectronic devices. The development of complementary colour OLEDs with blue and yellow can provide a simple approach to fabricate solution-processed white PhOLEDs.

Keywords: organic light-emitting diodes, solution-processed, binary blend.
\end{abstract}

\section{INTRODUCTION}

Organic light-emitting diodes (OLEDs) have many advantages over inorganic ones, such as their high contrast, bendability, self-illumination and low-power consumption $[1-4]$, thus resulting in their wide application in the flatpanel display and illumination. At present, the preparation methods of mainstream OLEDs include vacuum evaporation, ink-jet printing and solution-processing. Among them, solution-processing OLEDs have attracted much attention due to the advantages such as low cost, high material- utilization rate, simple fabrication process and large-area preparation [5-8].

However, the solution processed OLEDs faced some issues, for example, low efficiency, poor stability, unevenness and low repeatability. Some researchers have made great effort to solve them. Chiba et al. improved the performance of solution-processed OLEDs by interface modification [9]. Doh et al. demonstrated a soluble blue phosphorescent OLEDs (PhOLEDs) with a small molecular mixed host system [10]. We have also reported multicomponent host-guest systems to improve the efficiency and reduce the roll-off of green PhOLEDs [11]. In particular, the solution-processed small molecule host

\footnotetext{
* Corresponding author. Tel.: 56333362; fax: 56333362

E-mail address: yjliao@shu.edu.cn (Y. Liao)
}

and phosphorescent dopant materials have been paid intense attention in achieving efficient and stable PhOLEDs [12].

In addition, there are two approaches to fabricating white OLED, which are three-primary color mixing and complementary color mixing [13-16]. In this paper, we propose a simple preparation method of blue and yellow light by binary system, which is promising to be applied to the preparation of white OLEDs.

\section{EXPERIMENTAL SECTION}

\subsection{Materials}

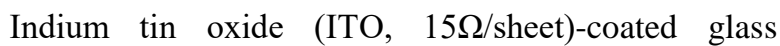
substrates were ordered from CSG Holding Co. Ltd (China). The bipolar and thermally activated delayed fluorescent (TADF) host DpAn-5BzAc was synthesized in our previous work $[11,17]$. The hole injection material PEDOT:PSS was purchased from Heraeus, Germany. The other organic functional molecules were obtained from eRay Optoelectronics Corp, China. All chemicals and reagents in this work were used as received from commercial sources without purification unless otherwise stated. The hole injecting material PEDOT:PSS was obtained from Heraeus. Other organic functional molecules were purchased from China e-Ray Optoelectronics. 


\subsection{Device manufacturing}

The configuration of the devices and chemical structures of host molecules are depicted in Fig. $1 \mathrm{a}$ and b, respectively. Manufacturing equipment using ITO/PEDOT:PSS (40 nm)/EML (20 nm)/TmPyPB (40 nm) /Liq (1 nm)/Al (100 nm) configuration, as shown in Fig. 1, ITO (indium tin oxide) was used as the anode, PEDOT:PSS (conductivity $2 \times 10^{-4} \mathrm{~S} / \mathrm{cm}$ ) was used as the hole injection layer; 1,3,5-tris(m-pyridin-3-ylbenzene) Benzo)benzene (TmPyPB) is used as an electron transport layer; 8-hydroxyquinolinyllithium (Liq) and $\mathrm{Al}$ are an electron injection layer and a cathode, respectively. As a common electron injection layer material, Liq has excellent electron transport characteristics and matches the electron transport layer in terms of energy level, as shown in Fig. 1 a. The prepared ITO glass substrate was firstly treated with detergent, deionized water, acetone and isopropanol in uv-ozone environment for about 15 minutes. Then, a $40 \mathrm{~nm}$ PEDOT: PSS film is dripped onto the ITO surface. After baking at $130{ }^{\circ} \mathrm{C}$ for 20 minutes, transfer the substrate to a nitrogen-filled glove box. The mCP, DpAn-5BzAc, PVK, FIrpic and EPY10 were all dissolved in chloroform with a concentration of $10 \mathrm{mg} / \mathrm{ml}$.The an emissive layer (EML) coating was then spin-coated and annealed at $65^{\circ} \mathrm{C}$ for 15 minutes to remove residual solvents. Finally, the upper layers which are the TmPyPB of $40 \mathrm{~nm}$, the Liq of $1 \mathrm{~nm}$ and the $\mathrm{Al}$ of $100 \mathrm{~nm}$ were sequentially evaporated through a shadow mask to complete device fabrication in a vacuum chamber at a base pressure of about $1.0 \times 10^{-6} \mathrm{mbar}$. The entire organic layer and the Al cathode were deposited without exposure to air, wherein the active area of the OLED was $4 \mathrm{~mm}^{2}$.

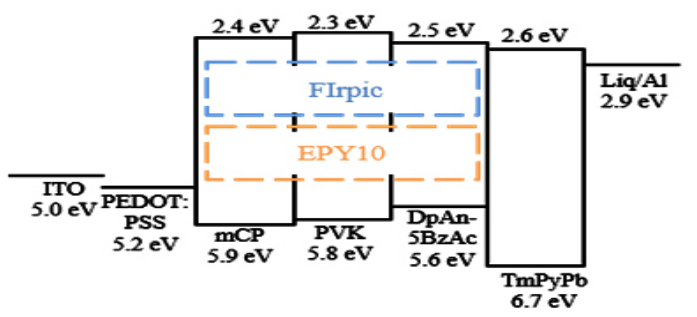

a
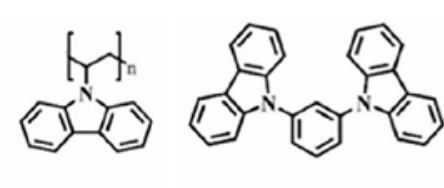

$\mathrm{mCP}$

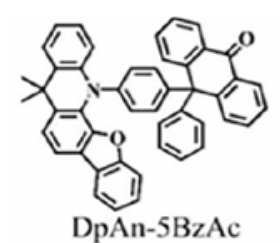

b

Fig. 1. a - the device configuration and the energy level diagram; $\mathrm{b}$-the chemical structures of the hosting materials in light-emitting layer

\section{RESULTS AND DISCUSSION}

\subsection{EL properties of the blue solution-processed PhOLEDs}

Here, we fabricated three solution-processed blue PhOLEDs with different host-guest system, which are a single host of mCP, and two binary hosts of mCP:PVK and mCP:DpAn-5BzAc, following the structure of ITO/PEDOT: PSS (40 nm)/host: $10 \mathrm{wt}$ \% FIrpic [18, 19] $(20 \mathrm{~nm}) / \mathrm{TmPyPB}(40 \mathrm{~nm}) / \mathrm{Liq}(1 \mathrm{~nm}) / \mathrm{Al}(100 \mathrm{~nm})$. The mCP was selected as host in PhOLEDs for their relatively high triplet energy (ET). The DpAn-5BzAc functioned as another small-molecule host for its high thermal stability, TADF characteristics and bipolar transport. The polymer PVK was used to be matrices for its good film-deposition evenness. The current density-voltage-luminance (J-V-L) characteristics, current efficiency-luminance (CE-L), the EL spectra, the external quantum efficiency (EQE) versus luminance and CIE diagram of the related devices are shown in Fig. 2 a-d, respectively. From Fig. 2 a, we can find that the turn-on voltage (Von) of Device B1(mCP:FIrpic) is same as that of Device B-3(mCP: DpAn5BzAc:FIrpic), which are both $5.2 \mathrm{~V}$, while the Von of Device B-2(mCP:PVK:FIrpic) is as high as $6.5 \mathrm{~V}$. In addition, Fig. $2 \mathrm{~b}$ reveals that Device B-3 employing the mCP:DpAn-5BzAc binary co-host exhibits superior current efficiency to Devices B-1 and B-2. The maximum CE of Device B-3 reached $16.61 \mathrm{~cd} / \mathrm{A}$, while the maximum CEs of Device B-1 and Device B-2 are only 10.54 and $7.87 \mathrm{~cd} / \mathrm{A}$, respectively. The enhanced performance of Device B-3 was attributed to the easier hole and electron injection from adjacent hole and electron transport layer compare to other systems [20,21]. The hole and electron barriers are only 0.4 and $0.1 \mathrm{eV}$ respectively for DpAn5BzAc-containing binary hosts, while the hole and electron barriers are 0.6 and $0.2 \mathrm{eV}$ respectively for PVK matrices.

It is worth to note that the two blue emission peaks (472 and $500 \mathrm{~nm}$ ) of Device B-3 can be observed, while the emission peak locate at $476 \mathrm{~nm}$ for both Devices B-1 and B-2, as shown in Fig. 2 c. The hole and electron trapping site on the host molecule of DpAn-5BzAc produce a greenish blue emission, leading to the second peak in EL spectra of Device B-3. The optoelectrical properties of devices with single and mixed binary host are summarized in Table 1.

Table 1. Summary of PhOLED blue characteristics based on different host materials

\begin{tabular}{|c|c|c|c|c|}
\hline Device $^{a}$ & $\mathrm{~V}_{\text {on }^{b}}{ }^{b}, \mathrm{~V}$ & $L_{\max }{ }^{c}, \mathrm{~cd} / \mathrm{m}^{2}$ & $C E_{\max }{ }^{d}, \mathrm{~cd} / \mathrm{A}$ & $\mathrm{EL}^{e}, \mathrm{~nm}$ \\
\hline B-1 & 5.2 & 12200 & 10.32 & 472 \\
\hline B-2 & 6.5 & 7852 & 7.87 & 472 \\
\hline B-3 & 5.2 & 17700 & 16.61 & 476 \\
\hline \multicolumn{5}{|c|}{$\begin{array}{l}{ }^{a} \text {-device configuration: ITO/PEDOT:PSS }(40 \mathrm{~nm}) / \mathrm{EML} \\
(20 \mathrm{~nm}) / \mathrm{TmPyPB}(40 \mathrm{~nm}) / \mathrm{Liq}(1 \mathrm{~nm}) / \mathrm{Al}(100 \mathrm{~nm}) ;{ }^{b}-\text { the } \\
\text { operating voltage at a brightness of } 1 \mathrm{~cd} / \mathrm{m}^{2} ;{ }^{c}-\text { the maximum } \\
\text { luminance; }{ }^{d}-\mathrm{CE} \text { at the maximum value; }{ }^{e}-\text { the EL emission } \\
\text { wavelength of the maximum intensity. }\end{array}$} \\
\hline
\end{tabular}

\subsection{EL properties of the yellow solution-processed PhOLEDs}

To verify the above inference, we also fabricated the yellow devices with single and binary blend host using a similar configuration to the blue devices, ITO/PEDOT:PSS $(40 \mathrm{~nm}) /$ host: $10 \mathrm{wt} \% \quad$ EPY10 $\quad(20 \mathrm{~nm}) / \mathrm{TmPyPB}$ $(40 \mathrm{~nm}) / \mathrm{Liq}(1 \mathrm{~nm}) / \mathrm{Al}(100 \mathrm{~nm})$, where the three types of hosts, mCP (Device Y-1), mCP:PVK (Device Y-2) and mCP:DpAn-5BzAc (Device Y-3). 


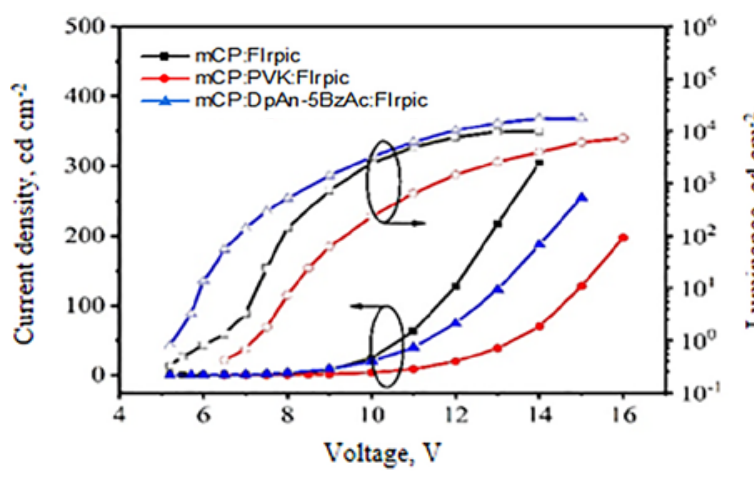

$\mathrm{a}$

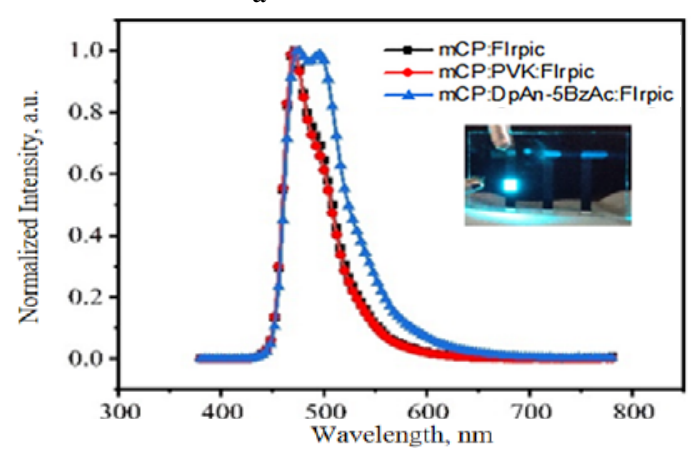

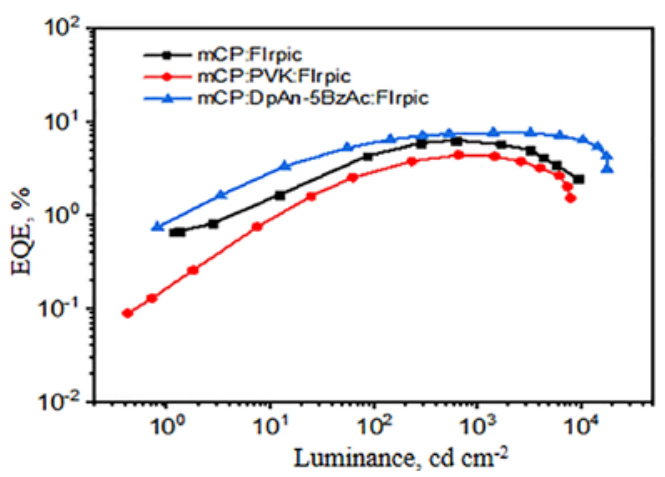

$\mathrm{b}$

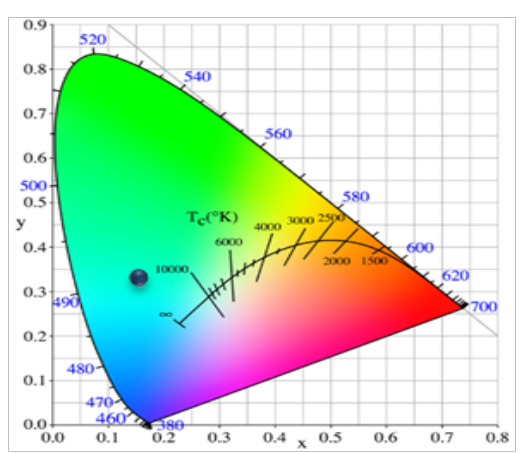

C

d

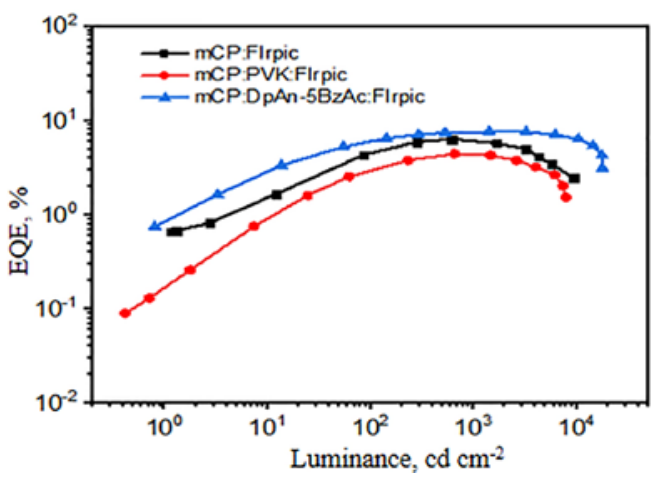

e

Fig. 2. Comparison of: a-J-V-L; b-CE-L; c-the corresponding EL spectral characteristics of single and binary host-based devices. The inset in Fig. 2 c is the emitting image of Device B-3; d-CIE diagram for blue device; e-the external quantum efficiency (EQE) versus luminance

The J-V-L characteristics, CE-L, the EL spectra, the EQE versus luminance and CIE diagram of the three devices are shown in Fig. $3 \mathrm{a}-\mathrm{d}$, respectively. The typical optoelectrical properties of devices with single and binary mixed hosts are summarized in Table 2.

Table 2. Summary of PhOLED yellow characteristics based on various host materials

\begin{tabular}{|c|c|c|c|c|}
\hline Device $^{a}$ & $\mathrm{~V}_{\text {on }}{ }^{b}, \mathrm{~V}$ & $L_{\max }{ }^{c}, \mathrm{~cd} / \mathrm{m}^{2}$ & $C E_{\max }{ }^{d}, \mathrm{~cd} / \mathrm{A}$ & $\mathrm{EL}^{e}, \mathrm{~nm}$ \\
\hline Y-1 & 3.1 & 11360 & 10.54 & 584 \\
\hline Y-2 & 5.2 & 9311 & 6.5 & 584 \\
\hline Y-3 & 3.2 & 14270 & 11.84 & 584 \\
\hline \multicolumn{5}{|c|}{$\begin{array}{l}{ }^{a} \text { - device configuration: glass/ITO/PEDOT:PSS }(40 \mathrm{~nm}) / \mathrm{EML} \\
(20 \mathrm{~nm}) / \mathrm{TmPyPB}(40 \mathrm{~nm}) / \mathrm{Liq}(1 \mathrm{~nm}) / \mathrm{Al}(100 \mathrm{~nm}) ;{ }^{b}-\text { the } \\
\text { operating voltage at a brightness of } 1 \mathrm{~cd} / \mathrm{m}^{2} ;{ }^{c}-\text { the maximum } \\
\text { luminance; }{ }^{d}-\mathrm{CE} \text { at the maximum value; }{ }^{e}-\text { the EL emission } \\
\text { wavelength at the maximum intensity. }\end{array}$} \\
\hline
\end{tabular}

Device Y-3 with the EML of mCP:DpAn5BzAc:EPY10 shows the best EL performance with maximum luminance and CE values of $14270 \mathrm{~cd} / \mathrm{m}^{2}$ and $11.84 \mathrm{~cd} / \mathrm{A}$, respectively. Most importantly, there is extremely reduced efficiency roll-off for DpAn-5BzAcbased yellow OLED. Moreover, the Von was the highest and the CE was lowest for PVK-based yellow device, which is consistent with our conjecture that the macromolecular material PVK will affect the performance of the solution-processed device. Therefore, we conclude that the binary small-molecule host is an appropriate candidate for solution-processed PhOLEDs.

\subsection{The energy transfer mechanisms of the binary system}

As shown in Fig. 4, we plot the energy transfer mechanisms of the binary-host-based Devices B-2 and B3. The Fig. 4 shows that the presence of macromolecular PVK blocks the energy transfer from mCP to FIrpic, resulting in reduced efficiency, higher turn-on voltage. 

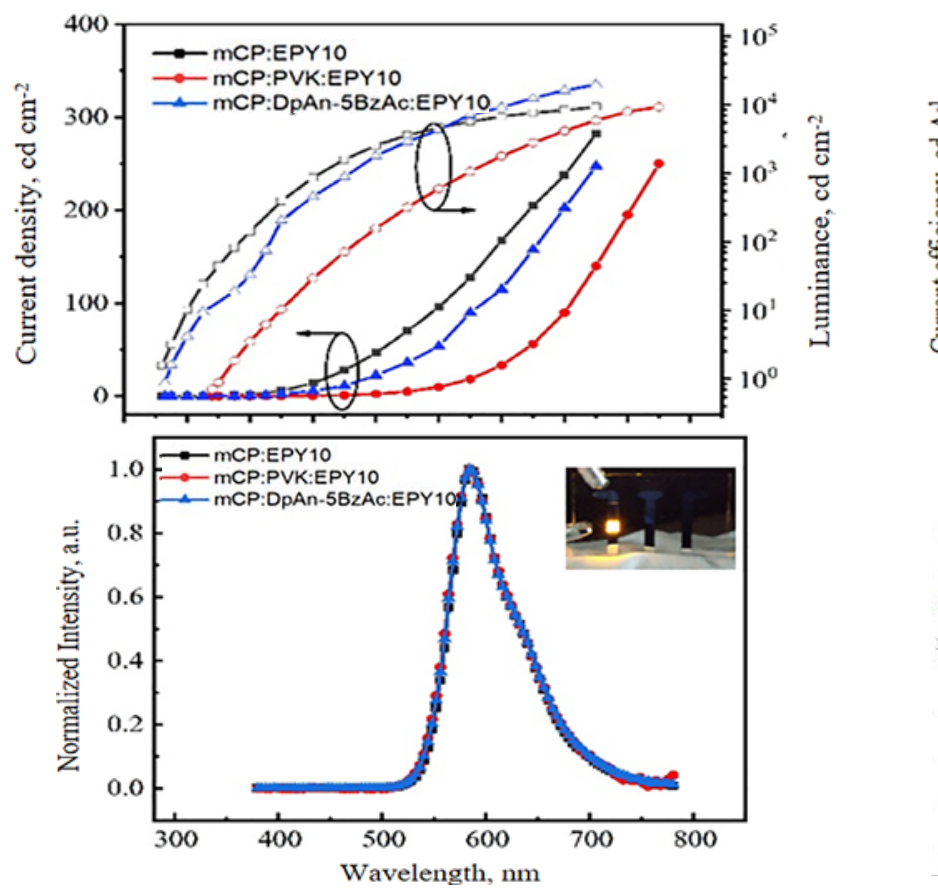

C
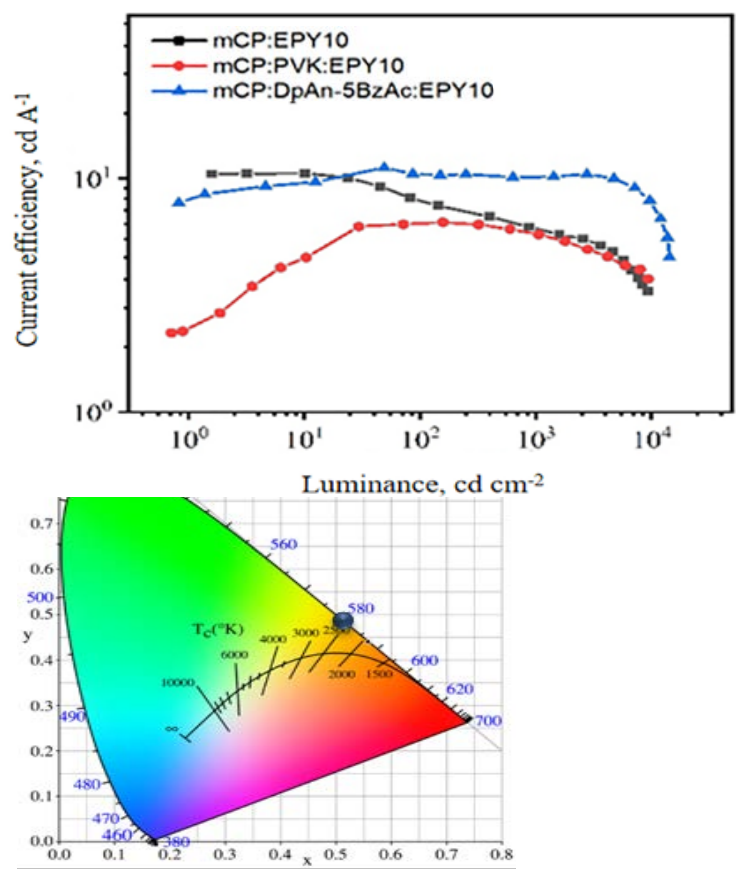

$\mathrm{d}$

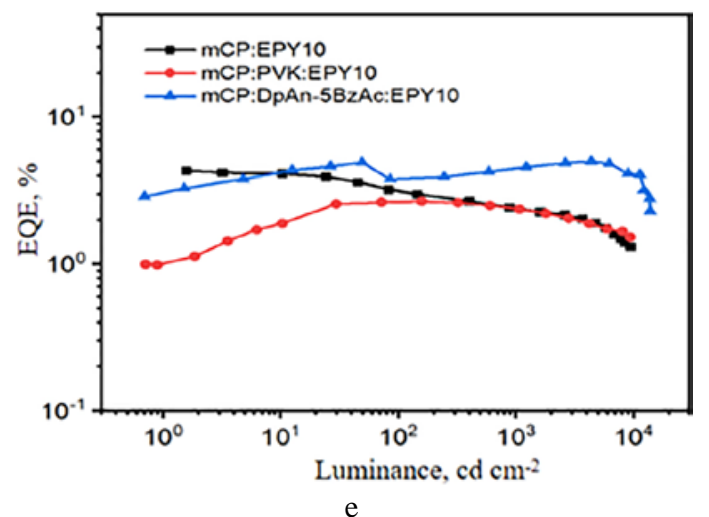

Fig. 3. Comparison of: $\mathrm{a}-J-V-L$; $\mathrm{b}-C E-L$; $\mathrm{c}-$ the corresponding EL spectral characteristics of single and binary host based devices. The inset in Fig. $3 \mathrm{c}$ is the emitting image of Device Y-3; d-CIE diagram for yellow device; e-the External quantum efficiency (EQE) versus luminance

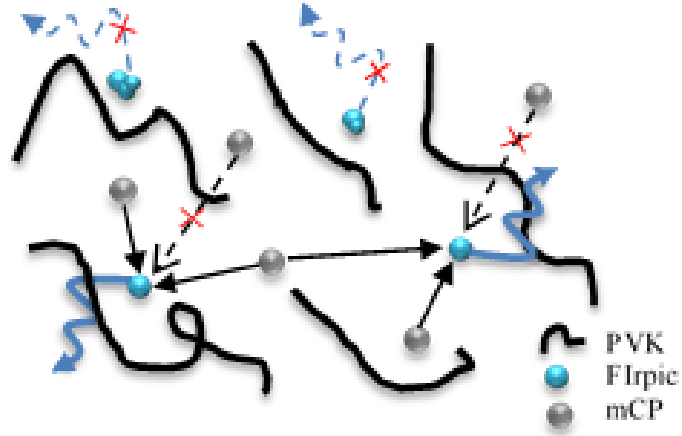

a

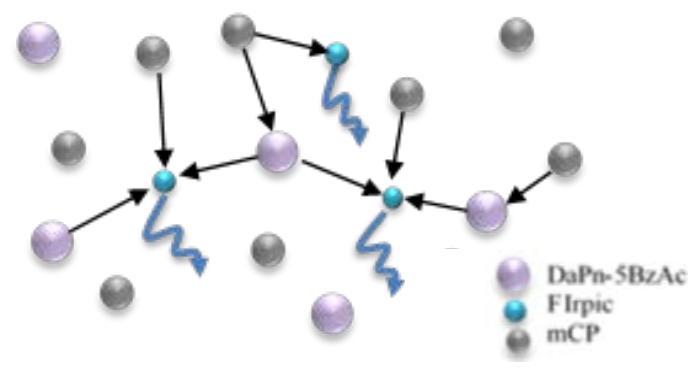

b

Fig. 4. The energy transfer mechanisms of: a-mCP:PVK:FIrpic; b-mCP:DaPn-5BzAc:FIrpic binary system

In addition, the presence of polymer making emitter more likely to aggregate, resulting in molecule-molecule quenching. Further, the deeper HOMO and shallower LUMO of PVK also severely hamper charge injection and/or transport in the device [22]. There are two possible energy transfer processes in the guest-host complex,
Förster transfer and Dexter transfer [23]. For phosphorescent acceptor in the emitting layer, the transfer mechanism of energy has been demonstrated to be a short range. Dexter transfer is the diffusion of excitons from donor to acceptor via the Wigner-Witmer spin conversation rules. 


\section{CONCLUSIONS}

In general, we have investigated the mixed host system using small molecular materials (mCP and DpAn-5BzAc) to enhance the hole injection ability of solution-processed OLEDs. The blue and yellow devices give efficiency with maximum luminance of 17700 and $14270 \mathrm{~cd} / \mathrm{m}^{2}$, peak CE of 16.61 and $11.84 \mathrm{~cd} / \mathrm{A}$, respectively, which mCP:DaPn5BzAc was chose as binary mixed hosts. In addition, the polymer PVK is found to reduce the performance of the device by severely hampering charge injection and transport characteristics. The improved performance of the binary-host-based device is realized by accelerating the balance of charge carrier, optimizing the miscibility of solution-processed EMLs, and improving the film of structural order. This work demonstrates a simple way to fabricate a high performance solution-processed PhOLEDs by using the mixed binary host system. This work could be applied to fabricate the white solution-processed OLED devices achieved by a simple method [23, 24].

\section{Acknowledgments}

This work was financially supported by the Science and Technology Commission of Shanghai Municipality Program (19DZ2281000; 17DZ2281700).

\section{REFERENCES}

1. Miao, Y., Wang, K., Zhao, B., Gao, L., Tao, P., Liu, X., Hao, Y., Wang, H., Xu, B., Zhu, F. HighEfficiency/CRI/Color Stability Warm White Organic LightEmitting Diodes by Incorporating Ultrathin Phosphorescence Layers in A Blue Fluorescence Layer Nanophotonics 7 2018: pp. 295-304.

https://doi.org/10.1515/nanoph-2017-0021

2. Wang, S., Qiao, M., Ye, Z., Dou, D., Chen, M., Peng, Y., Shi, Y., Yang, X., Cui, L., Li, J., Wei, B., Wong, W. Efficient Deep-Blue Electrofluorescence with An External Quantum Efficiency Beyond 10\% iScience 9

2018: pp. $532-541$.

https://doi.org/10.1016/j.isci.2018.10.026

3. Han, C.M., Zhang, Z., Ding, D.X., Xu, H. Dipole-Dipole Interaction Management for Efficient Blue Thermally Activated Delayed Fluorescence Diodes Chemistry Multidisciplinary 4 2018: pp. 2154-2167. https://doi.org/10.1016/j.chempr.2018.06.005

4. Wang, S.L., Yang, J.L., Xu, T., Dou, D.H., Tang, Z.Y., Gao, Z.X., Chen, M.Y., Guo, K.P., Yu, J.S., Plaind, J., Bachelot, R., Zhang, J.H., Wei, B. Highly Efficient and Foldable Top-emission Organic Light-Emitting Diodes Based on Ag-Nanoparticles Modified Graphite Electrode Organic Electronics 64 2019: pp. 146-153. https://doi.org/10.1016/j.orgel.2018.10.024

5. Liu, N.L., Ai, N., Hu, D.G., Yu, S.F., Peng, J.B., Cao, Y., Wang, J. Effect of Spin-Coating Process on The Performance of Passive-matrix Organic Light-Emitting Display Acta Physica Sinica 60 2011: pp. 087805.

6. Olivier, S., Ishow, E., Della-Gatta, S.M., Maindron, T. Inkjet Deposition of A Hole-Transporting Small Molecule to Realize a Hybrid Solution-Evaporation Green Top-Emitting OLED Organic Electronics 49 2017: pp. 24-32. https://doi.org/10.1016/j.orgel.2017.06.017

7. Kim, K., Kim, G., Lee, B.R., Ji, S., Kim, S.Y., An, B.W., Song, M.H., Park, J.U. High-Resolution
Electrohydrodynamic Jet Printing of Small-Molecule Organic Light-Emitting Diodes Nanoscale 7

2015: pp. $13410-13415$.

https://doi.org/10.1039/c5nr03034j

8. Zhu, M., Ye, T., He, X., Cao, X., Zhong, C., Ma, D., Qiu, J., Yang, C. Highly Efficient Solution-Processed Green and Red Electrophosphorescent Devices Enabled by SmallMolecule Bipolar Host Material Journal Materials Chemistry 21 2011: pp. 9326-9331. https://doi.org/10.1039/c1jm10987a

9. Chiba, T., Pu, Y.J., $\quad$ Hirasawa, M., $\quad$ Masuhara, A., Sasabe, H., Kido, J. Solution-Processed Inorganic-Organic Hybrid Electron Injection Layer for Polymer Light-Emitting Devices ACS Applied Materials \& Interfaces 4 2012: pp. 6104-6108. https://doi.org/10.1021/am301732m

10. Doh, Y.J., Park, J.S., Jeon, W.S., Pode, R., Kwon, J.H. Soluble Processed Low-Voltage and High Efficiency Blue Phosphorescent Organic Light-Emitting Devices Using Small Molecule Host Systems Organic Electronics 13 2012: pp. 586- 592. https://doi.org/10.1016/j.orgel.2012.01.003

11. Zhang, J.H., Guan, Y.X., Yang, J.L., Hua, W.Q., Wang, S.L., Ling, Z.T., Lian, H., Lan, W.X., Liao, Y.J., Lan, W.X., Wei, B., Wong, W.Y. Highly-Efficient Solution-Processed Green Phosphorescent Organic LightEmitting Diodes with Reduced Efficiency Roll-Off Using Ternary Blend Hosts Journal Materials Chemistry C 7 2019: pp. $11109-11117$.

https://doi.org/10.1039/c9tc02701g

12. Chen, M.Y., Zhao, Y., Tang, Z.Y., Zhang, B., Wei, B. Multifunctional Organic Emitters for High-Performance and Low-Cost Organic Light-Emitting Didoes Chemical Record 19 2019: pp. 1-12. https://doi.org/10.1002/tcr.201900005

13. Höfle, S., Schienle, A., Bernhard, C., Bruns, M., Lemmer, U., Colsmann, A. Solution Processed, White Emitting Tandem Organic Light-Emitting Diodes with Inverted Device Architecture Advanced Materials 26 2014: pp. $5155-5159$.

https://doi.org/10.1002/adma.201400332

14. Chiba, T., Pu, Y.J., Kido, J. Solution-Processed White Phosphorescent Tandem Organic Light-Emitting Devices Advanced Materials 27 2015: pp. 4681-4687. https://doi.org/10.1002/adma.201501866

15. Li, W.L., Sun, C., Yang, L.Q, Zhu, W.Q., Zhang, H., Cai, M., Zhang, X.W., Wei, B. Extremely Low ColorTemperature White Organic Electroluminescence Devices Based on The Control of Exciton Recombination Zone Physica Status Solidi A 9 2016: pp. 2400-2405. https://doi.org/10.1002/pssa.201600040

16. Zhang, M.Y., Wang, F.F., Wei, N., Zhou, P.C., Peng, K.J., Yu, J.N., Wang, Z.X., Wei, B. High Color Rending Index and High-Efficiency White Organic LightEmitting Diodes Based on The Control of Red Phosphorescent Dye-Doped Hole Transport Layer Optics Express 21 2013: pp. A173-A178. https://doi.org/10.1364/OE.21.00A173

17. Ye, Z.H., Ling, Z.T., Chen, M.Y., Yang, J.L., Wang, S.L., Zheng, Y.Q., Wei, B., Li, C., Chen, G., Shi, Y. Low Energy Consumption Phosphorescent Organic LightEmitting Diodes Using Phenyl Anthracenone Derivatives as The Host Featuring Bipolar and Thermally Activated Delayed Fluorescence RSC Advances 9 2019: pp. $6881-6889$. 
https://doi.org/10.1039/c8ra10658d

18. Tountas, M., Topal, Y., Kus, M., Ersoz, M., Fakis, M., Argitis, P. Water-soluble Lacunary Polyoxometalates with Excellent Electron Mobilities and Hole Blocking Capabilities for High Efficiency Fluorescent And Phosphorescent Organic Light Emitting Diodes Advanced Functional Materials 16 2016: pp. 2655-2665. https://doi.org/10.1002/adfm.201504832

19. Kozhevnikov, V.N., Zheng, Y.H., Clough, M., AlAttar, H.A., Hameed. A., Griffiths, G.C., Abdullah, K., Raisys, S. Cyclometalated Ir(III) Complexes for HighEfficiency Solution-Processable Blue PhOLEDs Chemistry of Materials 25 2013: pp. $2352-2358$. https://doi.org/10.1021/cm4010773

20. Ho, C.L., Wong, W.Y., Zhou, G.H., Yao, B., Xie, Z.Y., Wang, L.X. Solution-processible Multi-Component Cyclometalated Iridium Phosphors for High-Efficiency Orange-Emitting OLEDS and Their Potential Use as White Light Sources Advanced Functional Materials 17 2007: pp. 2595-2936. https://doi.org/10.1002/adfm.200601205

21. Yin, S.W., $\quad$ Yi, Y.P., $\quad$ Li, Q.X., $\quad$ Yu, G., $\quad$ Liu, Y.Q., Shuai, Z.G. Balanced Carrier Transports of Electrons and Holes in Silole-based Compounds - A Theoretical Study
Journal of Physical Chemistry A 110

2006: pp. $7138-7143$.

https://doi.org/10.1021/jp057291o

22. Wang, S.M., Wang, X.D., Yao, B., Zhang, B.H., Ding, J.Q., Xie, Z.Y., Wang, L.X. Solution-Processed Phosphorescent Organic Light-Emitting Diodes with Ultralow Driving Voltage and Very High Power Efficiency Scientific Reports 5 2015: pp. 12487. https://doi.org/10.1038/srep12487

23. He, Z., Wang, C., Zhao, J., Du, X., Yang, H., Zhong, $P$. Blue and White Solution-Processed Tadf-Oleds with Over 20\% EQE, Low Driving Voltages and Moderate Efficiency Decrease Based on Interfacial Exciplex Hosts Journal of Materials Chemistry C 7 2019: pp. 11806-11812. https://doi.org/10.1039/c9tc03468d

24. Ngo, P.S., Hung, M.K., Tsai, K.W., $\quad$ Sharma, S., Chen, S.A. Highly Efficient Solution-Processed Thermally Activated Delayed Fluorescence Bluish-Green and Hybrid White Organic Light-Emitting Diodes Using Novel Bipolar Host Materials ACS Applied Materials \& Interfaces 11 2019: pp. 45939-45948.

https://doi.org/10.1021/acsami.9b14168

(c) Guan et al. 2022 Open Access This article is distributed under the terms of the Creative Commons Attribution 4.0 International License (http://creativecommons.org/licenses/by/4.0/), which permits unrestricted use, distribution, and reproduction in any medium provided you give appropriate credit to the original author(s) and the source, provide a link to the Creative Commons license, and indicate if changes were made. 